\title{
Giulio Magli, Archaeoastronomy: Introduction to the Science of Stars and Stones
}

\author{
Cham, Switzerland: Springer International Publishing, 2016. Paperback, \\ 260 pages, colour illustrations. ISBN: 978-3319228815. £26.99.
}

\section{Javier Mejuto \\ Universidad Nacional Autónoma de Honduras javier.mejuto@unah.edu.hn}

This book, based on the author's eight years' teaching experience, is intended as an archaeoastronomy textbook for undergraduate students. The book broadly accomplishes its aims, as set out in the Introduction, to be "an up-to-date, easy-to-follow presentation of the subject" that

intends to arm the reader with the necessary set of instruments that will enable him to distinguish between serious archaeoastronomical research and the vast amount of pseudo-archaeological claptrap masquerading as archaeoastronomy which is readily available on the Web and in bookshops. (p. xi)

The book reflects the typical structure of Magli's cultural astronomy course; the chapters are arranged into three main parts, and each chapter is divided into sub-sections. The first part, "Methods", includes a basic explanation of astronomy and introduces methods in the field and how to interpret the data. The second part, "Ideas", has chapters on the relationship between astronomical knowledge and cultural development in different cultural expressions such as architecture, political power, social control and cultural landscape creation. Part III, "Places", contains case studies from the main cultural regions of the world. The selected exercises, almost forming an appendix, cover the main theoretical concepts of the book/course.

However, the book fails to provide a basic grounding in mathematics in astronomy, which might have been useful for students from different specialisms; new students in the archaeoastronomy classroom may have studied psychology, biology, medicine, archaeology, anthropology and so on over several years at university, but have no more than high-school mathematics. For these students, guides should include a mathematical section on topics such as spherical trigonometry and coordinates transformation; this kind of basic mathematical astronomy is commonly missing in archaeoastronomy books 
and, in my opinion, this is one of the main problems that is faced by new students in this discipline.

In Part I, the sub-section dedicated to calendars is extremely short, consisting of just four paragraphs (pp. 25-26); yet timekeeping, of which calendars is a cultural expression, is one of the most important tools in understanding many structures and their orientations to astronomical events. Aveni has observed that "chronology - setting up an ordered system of timekeeping to administer the needs of state - was one of the basic motives for ancient sky watching" (Aveni 1997, 105); while Krupp argues that the calendar "is much more than an array of numbers in sequence accompanied, perhaps, by a set of diverting pictures. Our ancestors understood its importance. They knew it had power: religious power, economic power, political power" (Krupp 1994, 157). The subject is perhaps particularly associated with Mesoamerican cultures, but timekeeping is also important in many other cultural regions, and so one might expect to have found in Magi's work a wider consideration of this particular topic, or at least a general overview.

As regards methodology, neither Magli's book nor the current review seeks to provide a profound analysis; it is a subject with a controversial history within the discipline of archaeoastronomy, and as such it is difficult to provide an adequate methodological discussion that covers the most-used methods. The author chooses to discuss a mix of classical and modern methods and instruments that includes the magnetic compass, clinometer and theodolite alongside Global Positioning Systems (GPS) and Virtual Globe (VG) software. I believe that readers would have appreciated a more comprehensive explanation of current technologies; for example, the Global Navigation Satellite System (GNSS), which includes different satellite constellations; the North American Global Positioning System (GPS); the Russian GLONASS; the European Galileo; the Chinese Beidou (in test period); and other, planned future ones. Similarly, there are Spatial Data Infrastructure (SDI) frameworks, within which Geographic Information Systems (GIS) are widely used in archaeology and emerging into use in cultural astronomy (Mejuto et al. 2012). Discussion of these resources would have provided a more complete overview of the methods and technologies used in archaeoastronomical research nowadays. The third chapter of Part I completes the section on methods and covers the principal and more common graphical and statistical tools used in archaeoastronomy in order to reconstruct ancient skies.

In Part II, "Ideas", Magli shows the social importance of astronomical knowledge in past cultures - an area that determines the relevance of archaeoastronomical studies. The author covers two important elements across the chapters: "Astronomy and Architecture at the Roots of Civilization" and "Astronomy, Power, and Landscapes of Power". In Chapter 4, Magli takes a journey through the ages, starting with the first humans and finishing with the so-called "astronomically anchored monumental architecture", asking when it was that people started to incorporate astronomical knowledge into their buildings (p. 69). Chapter 5 covers the relationship between sky, cosmovision and the derived power from this knowledge of cosmological order, and Magli argues that "[i]ndividuating the Cosmos - directions, celestial cycles, axis mundi and the like - and opening up communication between cosmic levels are [...] fundamental operations for human societies" (p. 80). The chapter concludes with an exploration of landscape shaping according 
to cultural worldviews, showing a profusion of examples from across the world, from Easter Island to Mesoamerica, Egypt and Europe. Chapter 6, which concludes Part II, is concerned with the scientific foundations of the discipline of archaeoastronomy, and as such looks somewhat out of place: it would have been better positioned at the beginning of the book rather than among chapters on the social aspects of astronomical knowledge.

The final part of the main text is entitled "Places", and surveys the best-known archaeoastronomical sites. Of course, it is virtually impossible to cover all the relevant sites in a short book, and especially so in a course-book aimed at undergraduates; an author can only aspire to cover a sufficient number of sites to give a general view of the richness of astronomical understanding in different cultural regions and to different peoples. Following the book's order, we encounter in turn "Megalithic Cultures of the Mediterranean" (Chapter 7); "Ancient Egypt", the cultural context of which the author of the book is an expert (Chapter 8); "Pre-Columbian Cultures" in Meso- and South America (Chapter 9); and "The Classical World" (Chapter 10). Besides the well-known Stonehenge, Newgrange, Giza, Karnak and Chichén Itzá, many lesser known places are mentioned, including Taulas in Spain, Uxmal in Mexico and Akragas in Italy.

The 32 exercises at the back of the book are mainly focused on the Sun, the Moon, Venus and the stars from an astronomical point of view, and the significance of horizon and latitude. The last few exercises cover statistics and virtual fieldwork as they appear in the corresponding chapters.

This book is indeed a proper framework, as it is intended to be, for designing archaeoastronomy courses for undergraduate students - a framework that can be implemented by adding or focusing on the parts our students need most, depending on their background or the cultural region they are working on. This kind of material is a rarity, and so it should be among our library volumes.

\section{References}

Aveni, A., 1997. Stairways to the Stars: Skywatching in Three Great Ancient Cultures. New York: John Wiley \& Sons.

Krupp, E. C., 1994. Echoes of the Ancient Skies. New York: Dover.

Mejuto, J., J. Gómez Castaño and G. Rodríguez-Caderot, 2012. "GIS Techniques in Archaeology: An Archaeoastronomical Approach". In Archaeology, New Approaches in Theory and Techniques, edited by I. OllichCastanyer [online]. Accessed August 2016, https://tinyurl.com/new-approaches-2016 